Article

\title{
Inadequacies in Hospital Waste and Sewerage Management in Chattogram, Bangladesh: Exploring Environmental and Occupational Health Hazards
}

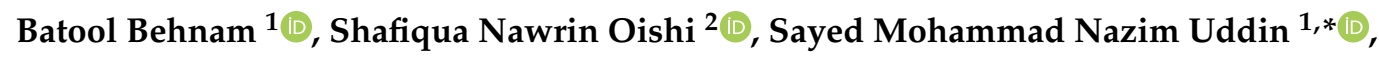 \\ Nazifa Rafa ${ }^{1}{ }^{\circ}$, Sayed Mohammad Nasiruddin ${ }^{3}$, AKM Moniruzzaman Mollah ${ }^{4}$ \\ and Ma Hongzhi ${ }^{5}$ \\ 1 Environmental Sciences Program, Asian University for Women, Chattogram 4000, Bangladesh; \\ batool@post.auw.edu.bd (B.B.); nazifa.rafa@auw.edu.bd (N.R.) \\ 2 Public Health Program, Asian University for Women, Chattogram 4000, Bangladesh; \\ shafiqua.oishi@post.auw.edu.bd \\ 3 School of Energy and Environmental Engineering, Beijing Key Laboratory of Resource-oriented Treatment of \\ Industrial Pollutants, University of Science and Technology Beijing, Beijing 100083, China; \\ smnasiruddin85@gmail.com \\ 4 Head of Science and Math Program, Asian University for Women, Chattogram 4000, Bangladesh; \\ moniruzzaman.mollah@auw.edu.bd \\ 5 Department of Environmental Engineering, University of Science and Technology Beijing, \\ Beijing 100083, China; mahongzhi@ustb.edu.cn \\ * Correspondence: sayed.uddin@auw.edu.bd
}

Received: 4 September 2020; Accepted: 29 October 2020; Published: 31 October 2020

check for updates

\begin{abstract}
Bangladesh has been grappling with the issues of improper hospital waste management. To reflect the inadequacies in existing management practices and the potential implications on the environment and health, this study evaluated the Knowledge, Attitude, and Practice (KAP) of doctors and nurses in a private and a public hospital in Chattogram city via a structured questionnaire survey. At the public hospital, $20.4 \%$ of the doctors and $6 \%$ of the nurses had occupational illnesses, compared to $36 \%$ of the doctors and $26.5 \%$ of the nurses at the private hospital. At the public hospital, $67.8 \%$ of the nurses wore PPE during waste collection, compared to $17.7 \%$ in the private hospital. Hospital wastes and occupational safety are not properly dealt with in both hospitals. An inadequacy was observed in the knowledge of hospital waste management among healthcare workers. The route of hospital wastes from the sources to the end destination was also traced via interviews and focus group discussions, which revealed that disposal practices of the hospital solid waste were environmentally unsustainable. In attempts to show opportunities for environmental and health risks from the hospital wastewater, this study also investigated the quality of the wastewater and tested it for the presence of resistant enteric pathogens. E. coli and S. aureus from both hospitals showed resistance against some common antibiotics used in Bangladesh. The physicochemical properties of the samples were nearly compliant with the Bangladesh Water Quality Standards for hospital wastewater. While more robust sampling and water quality analysis are required, this study provides basic water quality indicators and scope for future research to understand the apparent significant negative impact on the environment and health.
\end{abstract}

Keywords: antibiotic resistance; antimicrobial-resistant bacteria; healthcare; hospital waste; Knowledge, Attitude, and Practice (KAP); landfill; occupational safety; waste disposal 


\section{Introduction}

Healthcare waste encompasses all wastes produced within healthcare facilities, research centers, and laboratories related to medical procedures, including healthcare undertaken at home. About $75-90 \%$ of healthcare wastes are called general healthcare waste or non-hazardous waste, while the remaining $10-25 \%$ are hazardous waste [1]. In studies involving medical waste, four specific terms may be used: hospital waste, medical waste, regulated medical waste, and infectious medical waste [2]. To give clarity throughout the paper, the term hospital waste will be used to refer to the wastes that are generated from hospitals, healthcare clinics, or healthcare-related facilities.

Hospital waste management is a serious issue because of its intrinsic toxic and infectious nature; therefore, mismanagement or unsafe disposal of hospital wastes poses risks to all front-line workers. Improper healthcare waste management might lead to the pollution and contamination of soil, air, and surface and groundwater [3]. In several cases, groundwater near the landfill of pharmaceutical waste was found to be highly concentrated in heavy metals, causing damage to the aquatic ecosystem [4]. In developing countries, while the expansion of healthcare facilities and the increase of waste is one major problem, the lack of technological and financial sources to manage hospital waste properly becomes another issue [5], imposing greater environmental and occupational risks due to poor waste segregation, storage and transportation, and disposal practices [6]. In addition, lack of knowledge and awareness about hospital waste has been a concern amid inadequate hospital waste management facilities and ineffective policies [7].

In recent years, many studies have been carried out on medical waste management in Bangladesh, which mostly focused on the amount of waste that is produced by hospitals and the knowledge and attitude of healthcare workers about hospital waste $[8,9]$. A cross-sectional study conducted on nurses at Faridpur Medical College Hospital found that only $8 \%$ of the respondents had a sound knowledge of pharmaceutical wastes and only 7\% could answer questions about biomedical wastes [10]. In Rajshahi, the health and knowledge of hospital workers in public hospitals were found to be better than those from the private ones, even though the overall awareness and hospital waste management practices for both kinds of hospitals were below adequate [11]. Due to the lack of sound knowledge, the occupational risk is higher for these frontline workers. It is no surprise that doctors are one of the most high-risk people to be infected by COVID-19; 36 doctors have already died from the diseases and 1200 have tested positive in Bangladesh [12].

Worldwide, more than 3 million healthcare workers experience stressful skin injuries caused by contaminated sharp objects annually, resulting in 16,000 infections of hepatitis $C$ virus (HCV), 66,000 of hepatitis B virus (HBV), and about 1000 of Human Immunodeficiency Virus (HIV), causing 1100 deaths and notable disabilities [13]. This is more noticeable in developing countries due to the high prevalence in such regions [14]. In Dhaka, healthcare workers who had been in service for 7-10 years had a $6.3 \%$ prevalence of $\mathrm{HBV}$ and a $1 \%$ prevalence of $\mathrm{HCV}$ [15]. One study showed that within 15 days of contact with hospital waste, $41 \%$ of nurses, $60 \%$ of cleaners, and $57 \%$ of waste pickers/residents suffered from diseases including skin diseases, allergy, hepatitis B/C, diarrhea, and dysentery [16]. These events weaken the health-care system by affecting its workforce's productivity and effectiveness. Occupational health and safety are very important for the productivity of a society [17].

Health care workers are found to be ill-equipped for most of their time in service due to a lack of training [18]. For countries like Bangladesh, where Occupational Safety and Health (OSH) is rarely maintained as per the National OSH Policy [19], health workers find themselves unprepared for the health hazards surrounding hospital waste and thus fall victims to the harms caused by mismanagement [20]. 


\subsection{Improper Hospital Waste Management in Bangladesh}

\subsubsection{Management of Solid Waste}

In Bangladesh, the indiscriminate and improper disposal of hospital waste endangers the lives of healthcare workers and others who come into contact with this waste, causing diseases and illnesses to people. Hospital waste composes $5.7 \%$ of the total waste in Dhaka [21] and is disposed of openly in places such as City Corporation dustbins, dustbins near hospitals or holes dug in the ground, open!landfills, roadsides, drains, and rivers; $59 \%$ of the hospitals dispose of their wastes in municipal bins without segregation [22], even though $22.6 \%$ of the waste is infectious [23]. In other cities such as Rajshahi, hospital waste is disposed of together with other municipal waste in open landfills [24]. In Chattogram, while private hospitals usually produce more kilograms of waste per bed per day than public hospitals, there is a general lack of proper waste segregation in most, if not all, of the hospitals [25]. Such improper disposal methods put the health of the 400,000 waste pickers in Bangladesh at risk [26], causing several gastrointestinal, respiratory, and skin problems [27]. Situations worsen under certain conditions, such as those seen during the current COVID-19 pandemic, as the use of masks and gloves rise. Because some of these masks are made of plastic materials that are liquid resistant and non-biodegradable, they remain for a longer period in oceans and landfills [28]. For a developing country, as in the first month of the cases identified in Bangladesh, about 455 million surgical masks and 1216 million gloves had been used, resulting in over 4500 tons of disposable waste on top of the regular hospital waste [29], causing not only environmental hazards but also potentially contributing in the spread of the contagious disease.

\subsubsection{Management of Wastewater}

Mismanagement of hospital waste, including wastewater, leads to the emergence and spread of antimicrobial-resistant (AMR) bacteria, as the release of large amounts of antimicrobials in hospital wastewater initiates a continuous selective pressure that contributes to the proliferation of resistant microbes [30]. AMR has surfaced as one of the biggest threats to public health in the last few decades due to its responsibility in increasing the chances of clinical unresponsiveness to treatment and the rapid evolution of sepsis and septic shock. Antibiotics that are no longer useful for the treatment of infectious diseases cause stress on the nation's health expenditure and can lower the total GDP by reducing economic yields per household [31]. AMR infections have been attributed to the unsafe disposal of waste from health care facilities, among other places, and is prevalent in regions where prophylactic usage of antibiotics is frequent [32], such as in Bangladesh where there is a lack of proper surveillance, low awareness regarding antibiotic consumption, and a lack of trained healthcare professionals [33]. While even treated hospital wastewater has been responsible for the spread of multidrug-resistant microorganisms [34], Bangladesh treats only $17 \%$ of its total wastewater [35] due to the lack of enforceability of the Bangladesh Water Quality Standards, which may increase the risks of infections by resistant microbes. Several studies that assessed hospital wastewater, predominantly from Dhaka, found isolates of microorganisms such as E. coli and K. pneumoniae that displayed resistance against multiple commonly used antibiotics [36-39]. However, data regarding the environmental contamination with antimicrobial-resistant bacteria from hospital effluents from Chattogram still remains scarce, even though it is the second-largest city in the country.

Physicochemical characteristics are another widely used form of assessment of hospital effluents, but such studies are more often conducted on the effluents from textile and tannery industries [40-42], which contribute to a large part of Bangladesh's economy. However, the pollutant concentrations of physicochemical parameters such as Biological Oxygen Demand (BOD), Chemical Oxygen Demand (COD), Total Suspended Solids (TSS), and Total Dissolved Solids (TDS) are two to three times higher in hospital wastewater compared to domestic wastewater [43]. As a result, it is a crucial criterion to evaluate hospital wastewater despite the scarcity of data for comparison in Bangladesh. 


\subsection{Objectives}

This study attempted to illustrate the total hospital waste management scenario in Chattogram, Bangladesh, to reveal the potential environmental and health risks, and its aim is to serve as a scoping study. To assess compliances with standard protocols for occupational safety, it inquired into the safety measures taken by the healthcare employees of two hospitals by investigating the workers' Knowledge, Attitude, and Practices (KAP) regarding hospital solid waste management, with intentions to establish a comparison between the public and the private hospitals. The study also further explored the opportunities for environmental and health hazards posed by hospital solid waste and wastewater by tracing the route of these wastes from source to the final destination, as well as by conducting a physicochemical and microbiological characterization of the wastewater. Particularly, the presence of two enteric pathogens, Escherichia coli and Staphylococcus aureus, was determined, and their resistances against some common antibiotics were assessed.

Therefore, the study aimed to answer the following research questions: (i) What were the different kinds of safety measures taken by the hospital staff while handling hospital waste and how did these measures differ across public and private hospitals? (ii) How did the differences in safety measures across public and private hospitals lead to differences in the prevalence of occupational illnesses in healthcare workers, if any? (iii) How aware were the staff regarding some of the basic safety protocols and their responsibilities regarding waste management and how did this awareness differ across public and private hospitals? (iv) What was the route of the hospital waste from the source to the end destination? (v) To what extent did the physicochemical characteristics of the hospital wastewater vary from Bangladesh Water Quality Standards for hospital wastewater? (vii) Did the hospital wastewater carry strains of E. coli and S. aureus that were resistant to some common antibiotics?

\section{Methods}

This study was carried out from December 2018 to February 2019, using a cross-sectional design. Data for this study were collected using a structured questionnaire survey, formal and informal interviews, focus group discussions, and laboratory analysis of hospital wastewater. The laboratory work for hospital wastewater analysis was conducted in the lab of the Asian University for Women (AUW), located in Chattogram, Bangladesh.

The study was approved by the ethical review committee of the AUW. Before the data collection, written consents were obtained from the respondents. The objectives, procedures, risks, and benefits of participating in the study were explained to them prior to the interview. They were assured that the participation was voluntary and that they were free to withdraw at any time without any negative consequences. Moreover, the confidentiality of all the collected data and the privacy of the participants were ensured and maintained with the highest priority.

\subsection{Survey Methods}

\subsubsection{Questionnaire for KAP Survey}

The focus of this study was on hospitals that provide tertiary care; that is, those that provide highly specialized medical care to patients [44]. The whole Chattogram division has one public hospital that provides tertiary care, which is the Chattogram Medical College Hospital (CMCH), and about 140 privately run hospitals [45], most of which provide tertiary care. For this study, the public hospital, Chattogram Medical College Hospital $(\mathrm{CMCH})$, and a private hospital, Chattogram Maa-O-Shishu Hospital (CMOSH), were chosen. While $\mathrm{CMCH}$ is a general hospital, CMOSH is a maternal and child care focused hospital, although it does also provides services under other departments including surgery, medicine, Gynecology, Ophthalmology, ENT, Dermatology, STD, Psychiatry, etc. (see Appendix A).

The total population for this study was 198 from both the hospitals-99 nurses and doctors from the public hospital and 99 nurses and doctors from the private hospital. The study followed a consecutive 
sampling method, where participants were selected based on their convenient accessibility [46]. For better communication, only the nurses and doctors who knew English and had agreed to participate in the study were purposively chosen. A self-administrated questionnaire including a set of 39 questions was developed for the KAP survey regarding hospital waste and occupational safety measurements. The questionnaire was designed based on some of the guidelines provided by the Environmental Assessment and Action Plan (2004) [47] and the National Occupational Safety and Health Policy (2013) [19]. For nurses, the questionnaire was translated into Bangla for their convenience. Each survey took around 20-25 min to complete. Microsoft Excel 2010 was used for data analysis.

\subsubsection{Focus Group Discussions (FGDs) and Interviews}

Focus group discussions (FGD) were conducted with 10 sanitary workers/cleaners regarding the environmental and health impact of hospital waste, waste handling and disposal practices, and waste collection time in the hospital. Each FGD took about $90 \mathrm{~min}$. To understand the waste flow in Chattogram, directors of the hospitals and the Chief Executive Officer and the Chief Conservancy Officer of Chattogram City Corporation (CCC) had been interviewed to provide insights into the collection processes and destination of hospital waste in Chattogram City.

\subsection{Hospital Wastewater Quality Analysis}

Eight wastewater samples were collected from the hospitals, with four samples from each hospital (two blackwater samples and two greywater samples). Blackwater is the wastewater resulting from toilet flushing after use. These are initially collected in septic tanks in both hospitals. Greywater is the wastewater that results from washing, laundering, bathing, or showering. Both kinds of water are released in separate pipes from the hospitals but meet at the main drainage, or the municipal wastewater system, which also contains domestic wastewater. Samples of both blackwater and greywater were obtained from the outlet pipes of hospitals. Samples were also taken at a distance of five meters away from the drainage, as it was the closest point to the drainage that could be sampled by the researchers. Grab sampling was employed for water sample collection, and all samples were collected on the same weekday between 11:00 am to 03:00 pm. These samples were collected in sterile plastic bottles and were transported to the AUW laboratory within one hour. The samples were kept in the fridge at $4{ }^{\circ} \mathrm{C}$ for chemical and microbial analysis the next day.

\subsubsection{Physicochemical Analysis}

For all eight water samples, different parameters, namely, $\mathrm{pH}$, dissolved oxygen (DO), $\mathrm{BOD}_{5}$, salinity, conductivity, and TDS were measured and compared with national and international standards. These parameters were measured with the Hanna multi-parameters instrument available in the AUW lab. The analysis was done $24 \mathrm{~h}$ after the sample collection. The parameters were compared with the Bangladesh Water Quality Standards for hospital wastewater.

\subsubsection{Microbiological Analysis}

Escherichia coli isolation: The standard culturing method of streak plating was used for the isolation of E. coli; $0.1 \mathrm{~mL}$ of the wastewater from each sample was plated separately onto a small petri dish of Eosin Methylene Blue (EMB) agar, prepared in the AUW lab. The plates were then incubated at $37^{\circ} \mathrm{C}$ for $24 \mathrm{~h}$. After incubation, the plates were observed for the presence of E. coli. The blue-black colonies with a green metallic sheen were considered as E. coli colonies.

Staphylococcus aureus isolation: The standard culturing method streak plating was used to isolate Staphylococcus aureus; $0.1 \mathrm{~mL}$ of collected wastewater was plated on to a small petri dish of Mannitol Salt Agar (MSA), prepared in the AUW lab. The plates were then incubated at $37^{\circ} \mathrm{C}$ for $24 \mathrm{~h}$. After incubation, the plates were observed for the presence of Staphylococcus aureus. Staphylococcus aureus was identified if the color of the media changed to yellow. 


\subsubsection{Antibiotic Resistance Test}

The selection of antibiotics was based on the availability of antibiotic discs in Chattogram. Due to the restriction of financial resources, only the easily accessible and frequently prescribed antibiotics in the hospitals of Chattogram were chosen for this study, as unchecked usage of antibiotics has been attributed to the cause of AMR [32]. For the antibiotic resistance test, the disk diffusion method was used. The colonies isolated from the aforementioned microbiological analysis test were used to test for resistance against six antibiotics: tetracycline ( $30 \mu \mathrm{g} / \mathrm{disc})$, penicillin (10 units), ampicillin ( $25 \mu \mathrm{g} / \mathrm{disc})$, sulfamethoxazole-trimethoprim ( $25 \mu \mathrm{g} / \mathrm{disc})$, amoxicillin (30 $\mathrm{gg} / \mathrm{disc})$, and mecillinam (10 $\mu \mathrm{g} / \mathrm{disc})$. For this test, firstly, nutrient agar (NA) plates were prepared in the AUW research lab, and bacterial isolates were spread on the NA plates. Then, antibiotic disks were placed on the plates and incubated for $24 \mathrm{~h}$ at 37 degrees Celsius. The results were compared with the Clinical and Laboratory Standards Institute (CLSI), the American Society for Microbiology (ASM), and the British Society for Antimicrobial Chemotherapy (BSAC). The result was compared with these three standards because antibiotics with the mentioned concentration were not found in one standard; thus, the result was compared with the available result in different standards.

\section{Results and Discussion}

\subsection{Results of the KAP Study}

\subsubsection{Characteristics of the Population}

The characteristics of the study population are shown in Table 1. Among the doctors, most (37 in the public hospital and 27 in the private hospital) were found to be newly hired, with less than a year of experience, whereas, among the nurses, a larger group was found to have been working for over one to seven years for both hospitals. It was found that, among the participants, $65.3 \%$ of doctors were less than 25 years of age. Only $26.5 \%$ of the doctors of the public hospital were from the age group of $25-35$ years, whereas, $50 \%$ of the nurses of the public hospital belonged to this age group. However, in the private hospital, $66 \%$ of the doctors were aged between $25-35$ years; $69.4 \%$ of the private hospital's nurses also belonged to this age group. The number of nurses and doctors was chosen almost equally for a more reliable comparison of the results of the public and private hospitals.

Table 1. Characteristics of healthcare workers.

\begin{tabular}{ccccc}
\hline & $\begin{array}{c}\text { Chattogram Medical College Hospital } \\
\text { (CMCH) }\end{array}$ & $\begin{array}{c}\text { Chattogram Maa-O-Shishu Hospital } \\
\text { (CMOSH) }\end{array}$ \\
\hline Experience (year) & Doctors & Nurse & Doctors & Nurse \\
\hline$<1$ & 37 & 12 & 27 & 5 \\
$1-7$ & 11 & 28 & 21 & 37 \\
$8-10$ & 1 & 1 & 2 & 5 \\
$>15$ & 0 & 9 & 2 & 2 \\
Age (Year) & $\mathbf{N}(\%)$ & $\mathbf{N}(\%)$ & $\mathbf{N}(\%)$ & $\mathbf{N}(\%)$ \\
$<25$ & $32(65.3)$ & $11(22)$ & $12(24)$ & $5(10.2)$ \\
$25-35$ & $13(26.5)$ & $25(50)$ & $33(66)$ & $34(69.40)$ \\
$36-45$ & $1(2)$ & $8(16)$ & $3(6)$ & $9(18.4)$ \\
$>45$ & $3(6.1)$ & $6(12)$ & $2(4)$ & $1(2)$ \\
\hline
\end{tabular}

\subsubsection{Occupational Safety Observation}

Occupational safety measurement was not followed properly in both the hospitals studied, as shown in Table 2. In the public hospital (CMCH), $20.4 \%$ of the doctors and $6 \%$ of the nurses were found to have illnesses due to the nature of their occupations compared to $36 \%$ of the doctors and $26.5 \%$ of the nurses in the private hospital (CMOSH). In both hospitals, waste and safety management equipment and measures were checked through direct observations. These include bins for disposal of 
sharp objects (e.g., needles, blades) and non-sharp objects (e.g., used bandages, cotton). The respondents were asked to respond to the guidelines given to maintain precautions and the availability of hygiene maintenance options such as running water, soap/hand-wash, alcohol rub, waste receptacle (paddle bin), disinfectant/antiseptics (e.g., chlorine, hibitane), and Personal Protective Equipment (PPE). The responses of doctors and nurses about occupational safety measures were as follows: $40.8 \%$ of the doctors and $94 \%$ of the nurses in the public hospital responded that occupational safety measures were being maintained and $18.4 \%$ of doctors were unaware of whether occupational safety measures were being maintained. In the private hospital, $54 \%$ of the doctors and $22.4 \%$ of the nurses responded that occupational safety measures were being maintained, and $18 \%$ of doctors and $32.7 \%$ of the nurses stated that they were unaware of any such measures. In the public hospital, the nurses responded that, during waste collection, only $3.6 \%$ wore aprons, $3.6 \%$ wore gloves, $5.4 \%$ wore face masks and gloves, and $76.8 \%$ reported wearing complete PPE (apron, leg protector, gloves, face mask, eye protectors). In contrast, it was found that, in the private hospital, $26 \%$ of the nurses wore aprons during waste collection, $27.1 \%$ wore gloves, $13.5 \%$ used face masks and gloves, and only $17.7 \%$ wore complete PPE (apron, leg protector, gloves, face mask, eye protector).

Table 2. Occupational Safety of Healthcare Workers.

\begin{tabular}{|c|c|c|c|c|}
\hline \multirow{2}{*}{ Questions } & \multirow{2}{*}{\multicolumn{2}{|c|}{ Position }} & \multicolumn{2}{|c|}{ Hospital } \\
\hline & & & CMCH * & CMOSH * \\
\hline \multirow{7}{*}{$\begin{array}{l}\text { Had Illness Because of } \\
\text { Their Profession }\end{array}$} & \multirow{3}{*}{ Doctors (\%) } & Yes & 20.4 & 36.0 \\
\hline & & No & 63.3 & 62.0 \\
\hline & & Not Sure & 16.3 & 2.0 \\
\hline & \multirow{3}{*}{ Nurses (\%) } & Yes & 6.0 & 26.5 \\
\hline & & No & 94 & 36.7 \\
\hline & & Not Sure & 0 & 36.7 \\
\hline & \multirow{3}{*}{ Doctors (\%) } & (a) Yes & 40.8 & 54 \\
\hline & & (b) No & 36.7 & 28 \\
\hline Are occupational Safety Measures & & (c) Don't know & 18.4 & 18 \\
\hline \multirow[t]{8}{*}{ Observed in Your Hospital? } & \multirow{3}{*}{ Nurses $(\%)$} & (a) Yes & 94 & 22.4 \\
\hline & & (b) No & 4 & 44.9 \\
\hline & & (c) Don't know & - & 32.7 \\
\hline & \multirow{6}{*}{ Doctors (\%) } & (a) Apron & 18.2 & 15.9 \\
\hline & & (b) Leg protector & 8 & 14 \\
\hline & & (c) Gloves & 27.3 & 26.2 \\
\hline & & (d) Face Mask and Gloves & 27.3 & 22.4 \\
\hline & & (e) Face Mask/Apron/Gloves/Eye Protector & 9.1 & 6.5 \\
\hline What Safety Measures Are Taken & & (f) All & 10.2 & 15 \\
\hline \multirow[t]{6}{*}{ During Waste Collection? } & \multirow{6}{*}{ Nurses (\%) } & (a) Apron & 3.6 & 26 \\
\hline & & (b) Leg protector & 7.1 & 8.3 \\
\hline & & (c) Gloves & 3.6 & 27.1 \\
\hline & & (d) Face Mask and Gloves & 5.4 & 13.5 \\
\hline & & (e) Face Mask/Apron/Gloves/Eye Protector & 3.6 & 7.3 \\
\hline & & (f) All & 76.8 & 17.7 \\
\hline
\end{tabular}

* $\mathrm{CMCH}$ (Chattogram Medical College Hospital) and CMOSH (Chattogram Maa-O-Shishu Hospital).

According to the responses, occupational safety measures were observed more in the public hospital than in the private hospital. Consequently, the number of doctors and nurses who had illnesses because of their professions was found to be higher in private hospitals. However, a relation was observed between the likelihood of developing occupational illnesses and the number of years worked in the hospital-those who had been working longer were likely to develop illnesses in the private hospital. Complete PPE was used more frequently in the public hospital compared to the private hospital, which could have contributed to the relatively low occupational hazard in the public hospital.

The results are similar to the findings of the study that had been undertaken in the Rajshahi division of Bangladesh, which found that healthcare workers from public hospitals were not only more likely to undertake safety measures such as gloves, goggles, masks, sanitizers, boots, gasmasks, and safety dresses when handling hospital wastes, attributed to the training provided in such hospitals, 
but occupational diseases also tended to be less frequent among workers of public hospitals compared to those from private ones [11].

\subsubsection{Knowledge of Healthcare Workers}

Table 3 depicts the knowledge of healthcare workers regarding hospital waste management systems. The number of doctors who knew about hospital waste was $73.5 \%$ in $\mathrm{CMCH}$, compared to $64 \%$ of doctors in CMOSH. Similarly, the percentage of nurses who knew about hospital waste was $96 \%$ in $\mathrm{CMCH}$, in contrast to $32.7 \%$ in CMOSH. Additionally, knowledge about the impact of hospital waste on the environment was noted by $75.5 \%$ of doctors and $98 \%$ of nurses in the public hospital, and $76 \%$ of doctors and $22.4 \%$ of nurses in the private hospital. This study shows that a higher number of nurses have knowledge about hospital waste, which is congruent with the findings for public hospitals in Africa [48,49]. However, whereas this study shows a gap in knowledge among the doctors in the private hospital, previous studies conducted in Bangladesh, specifically in Dhaka, depict doctors having adequate knowledge about hospital waste [50], as did another study that was done in the city, Gazipur [51]. Within $\mathrm{CMCH}$, the percentage of nurses who knew about hospital waste was higher compared to the percentage of doctors. However, this percentage was not the same in $\mathrm{CMOSH}$, where awareness was lower in nurses than in doctors. This is because, in public hospitals, nurses are often trained before starting their jobs in hospitals while, in private hospitals, there is no such training before the start of their profession, which is why their knowledge level about hospital waste is generally lower than doctors.

Table 3. Awareness of Healthcare Workers about Hospital Waste.

\begin{tabular}{|c|c|c|c|c|}
\hline \multirow{2}{*}{ Awareness } & \multirow{2}{*}{\multicolumn{2}{|c|}{ Position }} & \multicolumn{2}{|c|}{ Hospital } \\
\hline & & & СMCH * & $\mathrm{CMOSH}^{*}$ \\
\hline \multirow{7}{*}{ Do You Know About Hospital Waste? } & \multirow{4}{*}{ Doctors (\%) } & (a) Yes & 73.5 & 64 \\
\hline & & (b) No & 8.2 & 4 \\
\hline & & (c) little information & 18.4 & 30 \\
\hline & & (a) Yes & 96 & 32.7 \\
\hline & \multirow[t]{3}{*}{ Nurses (\%) } & (b) No & - & 18.4 \\
\hline & & (c) little information & 4 & 49 \\
\hline & & (a) Yes & 75.5 & 76 \\
\hline \multirow{6}{*}{$\begin{array}{l}\text { Do You Know About the Impact of } \\
\text { Hospital Waste on the Environment? }\end{array}$} & \multirow{3}{*}{ Doctors (\%) } & (b) No & 8.2 & 8 \\
\hline & & (c) little information & 14.3 & 14 \\
\hline & & (d) Didn't Answer & 2 & 2 \\
\hline & \multirow{3}{*}{ Nurses (\%) } & (a) Yes & 98 & 22.4 \\
\hline & & (b) No & - & 44.9 \\
\hline & & (c) little information & 2 & 32.7 \\
\hline \multirow{6}{*}{$\begin{array}{l}\text { Are There Clearly Defined Procedures for } \\
\text { the Collection of Waste for Specified Units } \\
\text { in the Hospital? }\end{array}$} & \multirow{3}{*}{ Doctors $(\%)$} & (a) Yes & 40.8 & 52 \\
\hline & & (b) No & 32.7 & 22 \\
\hline & & (c) Don't know & 26.5 & 26 \\
\hline & \multirow{3}{*}{ Nurses (\%) } & (a) Yes & 78 & 18.4 \\
\hline & & (b) No & 18 & 51 \\
\hline & & (c) Don't know & 4 & 30.6 \\
\hline \multirow{6}{*}{$\begin{array}{l}\text { Are Infectious Wastes Labeled with } \\
\text { Biohazard Symbol? }\end{array}$} & \multirow{3}{*}{ Doctors (\%) } & (a) Yes & 32.7 & 36 \\
\hline & & (b) No & 34.7 & 24 \\
\hline & & (c) Don't know & 30.6 & 40 \\
\hline & \multirow{3}{*}{ Nurses (\%) } & (a) Yes & 76 & 16.3 \\
\hline & & (b) No & 22 & 34.7 \\
\hline & & (c) Don't know & 2 & 49 \\
\hline
\end{tabular}

${ }^{*} \mathrm{CMCH}$ (Chattogram Medical College Hospital) and CMOSH (Chattogram Maa-O-Shishu Hospital).

While the findings of the study have shown similar occupational safety measures and knowledge of healthcare workers to the one conducted in the Rajshahi division [11], the study reveals a better scenario in Chattogram, compared to other areas such as Gazipur [51] in Bangladesh. 


\subsubsection{Attitudes of Healthcare Workers}

To survey the behavior of doctors and nurses toward hospital waste management, four main questions were asked, as shown in Table 2. In the public hospital, $83.7 \%$ of the doctors and $76 \%$ of the nurses felt that hospital waste management was the responsibility of the public. In the private hospital, $76 \%$ of the doctors and $26.8 \%$ of the nurses felt that hospital waste management was the government's responsibility.

Additionally, $87.8 \%$ and $98 \%$ of doctors and nurses, respectively, of the public hospital, and $80 \%$ and $28.6 \%$ of doctors and nurses, respectively, of the private hospital agreed that waste management requires the teamwork of different groups of people.

In the public hospital, $75 \%$ of the doctors and $100 \%$ of the nurses believed that the proper handling of hospital waste was very important. In the private hospital, $78 \%$ of the doctors and $49 \%$ of the nurses thought that proper handling of hospital waste was very important. The remaining reported that proper handling of hospital waste was not of much importance (Table 4). Another study has revealed similar results, where a higher number of healthcare workers in public hospitals viewed proper hospital waste management as important compared to those from private ones [11].

Table 4. The Attitude of Doctors and Nurses toward Hospital Waste Management

\begin{tabular}{|c|c|c|c|c|}
\hline \multirow{2}{*}{ Attitude } & \multirow{2}{*}{\multicolumn{2}{|c|}{ Position }} & \multicolumn{2}{|c|}{ Hospital } \\
\hline & & & СМCH ${ }^{*}$ & $\mathrm{CMOSH}^{*}$ \\
\hline \multirow{5}{*}{$\begin{array}{l}\text { Safe Management of Hospital Waste is the } \\
\text { Government's Responsibility }\end{array}$} & \multirow{4}{*}{ Doctors (\%) } & (a) Agree & 83.7 & 76.0 \\
\hline & & (b) Disagree & 12.2 & 12.0 \\
\hline & & (c) Cannot Comment & 4.1 & 12.0 \\
\hline & & (a) Agree & 76.0 & 28.6 \\
\hline & \multirow[t]{2}{*}{ Nurses (\%) } & (b) Disagree & 22.0 & 30.6 \\
\hline \multirow{8}{*}{$\begin{array}{l}\text { Waste Management Requires Teamwork; } \\
\text { No Single Class of People is Responsible for } \\
\text { the Safe Management of Hospital Waste }\end{array}$} & & (c) Cannot Comment & 2.0 & 40.8 \\
\hline & \multirow{3}{*}{ Doctors (\%) } & (a) Agree & 87.8 & 80.0 \\
\hline & & (b) Disagree & 10.2 & 8.0 \\
\hline & & (c) Don't know & 2.0 & 12.0 \\
\hline & \multirow{3}{*}{ Nurses (\%) } & (a) Agree & 98.0 & 28.6 \\
\hline & & (b) Disagree & 2.0 & 30.6 \\
\hline & & (c) Don't know & - & 40.8 \\
\hline & \multirow{3}{*}{ Doctors (\%) } & (a) Very important & 75.5 & 78.0 \\
\hline \multirow{4}{*}{$\begin{array}{c}\text { How Do You Rate the Importance of } \\
\text { Hospital Waste Handling? }\end{array}$} & & (b) Important & 24.5 & 22.0 \\
\hline & & (c) Not important & - & - \\
\hline & \multirow{3}{*}{ Nurses (\%) } & (a) Very important & 100.0 & 49.0 \\
\hline & & (b) Important & - & 46.9 \\
\hline \multirow{7}{*}{$\begin{array}{c}\text { Up to What Extent Do You Feel You Are } \\
\text { Responsible for Hospital } \\
\text { Waste Management? }\end{array}$} & & (c) Not important & - & 4.1 \\
\hline & \multirow{3}{*}{ Doctors (\%) } & (a) Very Much & 73.5 & 56.0 \\
\hline & & (b) Very little & 22.4 & 32.0 \\
\hline & & (c) Not at All & 4.1 & 12.0 \\
\hline & \multirow{3}{*}{ Nurses (\%) } & (a) Very Much & 92.0 & 24.5 \\
\hline & & (b) Very little & 8.0 & 65.3 \\
\hline & & (c) Not at All & - & 10.2 \\
\hline
\end{tabular}

* $\mathrm{CMCH}$ (Chattogram Medical College Hospital) and CMOSH (Chattogram Maa-O-Shishu Hospital).

One of the gaps, in this case, is the lack of a clear understanding of the procedures of collecting waste, as well as of the importance of proper waste disposal, which varies among healthcare workers in both hospitals. The findings suggested that about $41 \%$ of doctors from the public hospital and $52 \%$ from the private hospital (Table 2) had a clear understanding of the procedure of collecting and/or handling the hospital waste, as per the hospital policies. The remaining were either unsure or completely unaware of such instructions by the hospital authorities. Conversely, whereas $78 \%$ of the nurses of the public hospital stated that there were clear procedures for waste management, only $18.4 \%$ of the nurses in the private hospital were aware of such procedure. Moreover, other than the $76 \%$ and $16.3 \%$ of the nurses from the public and the private hospitals, respectively, who reported that the infectious wastes were labeled with biohazard signs, nurses from the private hospital and doctors from both the hospitals 
showed little understanding or awareness regarding whether and why the labels were being used (Table 3). Therefore, the gap in the proper understanding of the importance of handling hospital waste can be linked to the unclear instructions provided by the authorities and/or an absence of training within the staff in proper waste handling. In the study done in Rajshahi, $91 \%$ of the employees from the public hospital were found to be trained in hospital waste management, while none were found to be trained in the private hospital [11]. In addition, nearly half of the healthcare workers surveyed in the Gazipur Sardar Hospital, a public hospital, had not been trained in the management of biomedical waste [51].

Additionally, $73.5 \%$ of the doctors and $92 \%$ of the nurses in the public hospital and $56 \%$ of the doctors and $24.5 \%$ of the nurses in the private hospital responded that they were responsible for hospital waste management while $4.1 \%$ of the doctors in the public hospital and $12 \%$ of doctors and $10.2 \%$ of nurses in the private hospital felt that they were not responsible at all for hospital waste management.

The attitudes of doctors and nurses were different from each other in both hospitals. In the public hospital, the nurses displayed a more positive attitude toward waste management than doctors. In comparison, the doctors showed a more positive attitude toward hospital waste management than nurses in the private hospital. A study in Bangalore, India, showed that doctors and nurses had a more positive attitude toward hospital waste management compared to other employees (lab technicians, cleaning staff) [52]. This difference can be attributed to two reasons; one being that nurses and doctors had more awareness and knowledge than the rest of the hospital staff, and another being that nurses and doctors are more likely to deal with hospital wastes, except the cleaning staff, who generally lack knowledge and awareness regarding the impacts of hospital waste due to their lower educational achievements.

One study done in Chattogram had found that, despite the presence of color-coded drums in public hospitals, the wastes were not segregated according to the codes [25]. There was no such distinction between waste in private hospitals. The study also found that some staff were illegally selling untreated hospital waste to recycling shops.

\subsection{Hospital Waste Flow in Chattogram}

The interviewees and FGD participants revealed that hospital waste is collected in specific and separate vehicles. They further mentioned that the waste dumping ground of CCC, which is approximately 10 acres of land, is located in Halishahor and that it is an open landfill. All the waste from Chattogram is dumped there, including hospital wastes, but there is a small portion of the land designated for hospital waste, which is still an open landfill. Collected wastes from hospitals are dumped in this landfill. The facility does not have any waste processing (recycle, reuse, incineration, or burning or burial of the waste) system for hospital waste. The route of the hospital waste flow, starting from its source, is shown in Figure 1, below, and was constructed using the information obtained from interviews with the CCC officials.

The CCC informed us that the two main challenges it has been facing are the lack of skilled workers and adequate land for dumping. Overall, the CCC collects 2500 tons of various types of wastes per day. One of the key informants mentioned that the existing landfill is already overloaded. However, recently they have introduced the Waste to Energy program with the Power Development Board (PDB).

The main drainage carries both hospital wastewater and household effluents. The municipal wastewater is then directly discharged into the Karnaphuli river. Currently, there is no sewerage treatment plant in Chattogram. However, as part of the drainage and sanitation master plan of the Chittagong Water Supply and Sewerage Authority (CWASA), construction has begun on the first sewage treatment plant, out of the six that were planned, which will be handling water from the 72,502 households located in the Halishahar, Agrabad, New Market, Lalkhan Bazar, Jamal Khan, and Kotwali areas [53]. 


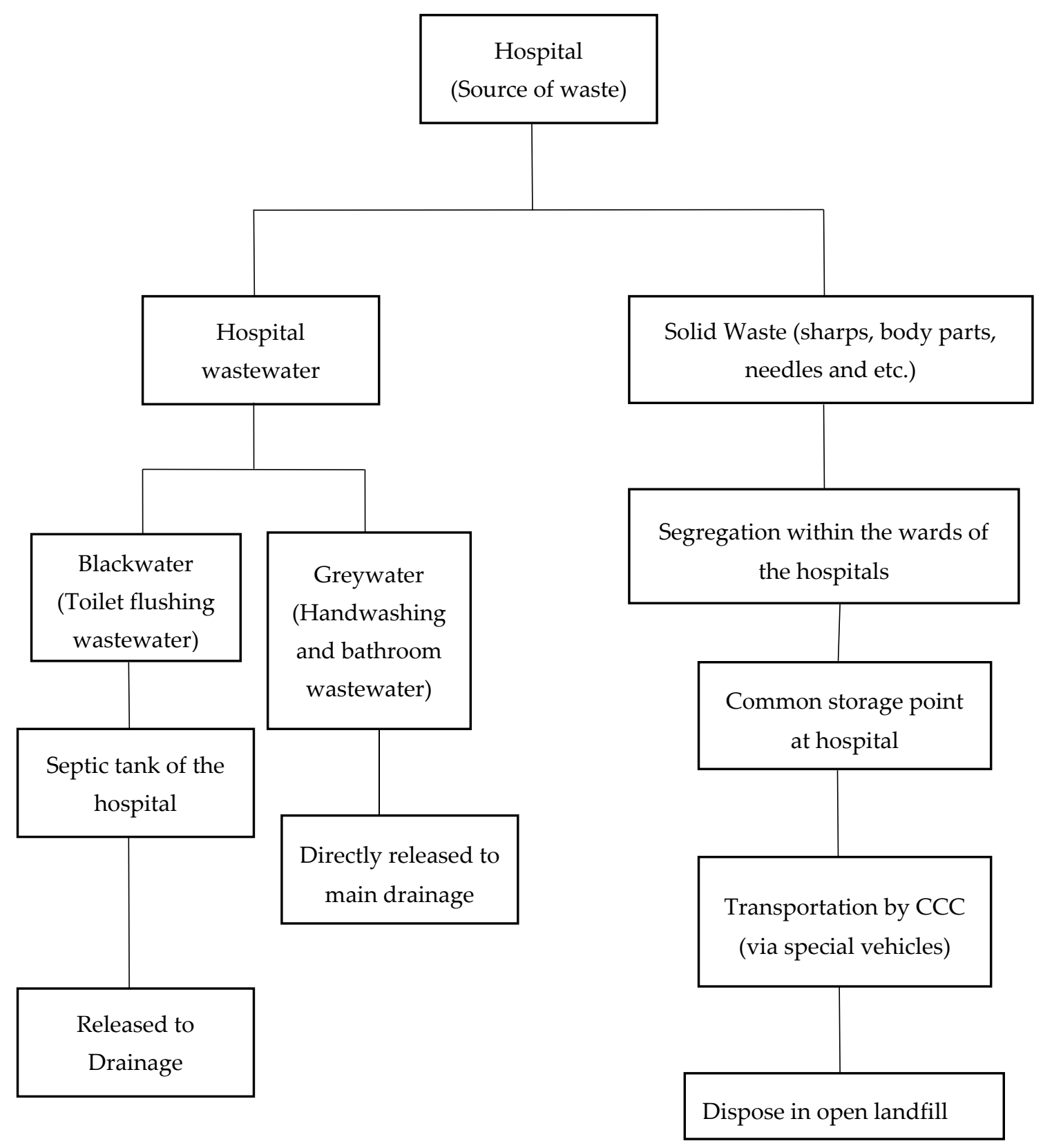

Figure 1. Route of Hospital Waste Flow in Chattogram City.

\subsection{Hospital Wastewater Quality Test}

\subsubsection{Presence of Enteric Pathogens}

Table 5 shows the presence of enteric pathogens in the samples. The water samples from Chattogram Medical College Hospital, collected from pipe outlets for both grey- and blackwater, did not contain E. coli (Figure A1) but had some other enteric bacteria, namely S. aureus (Figure A2). Water collected five meters away from drainage through which greywater was flowing (CMCH-2) contained E. coli (shown in Figure A1) and S. aureus (shown in Figure A2) (CMCH-2). The common drainage had effluent water from different households and other sectors, which may have contributed most of the results showing the presence of enteric pathogens for those collected from the drainage. 
Table 5. Water Sample Results.

\begin{tabular}{|c|c|c|c|c|}
\hline \multirow[b]{2}{*}{ Bacteria } & \multicolumn{4}{|c|}{ Chattogram Medical College Hospital (CMCH) } \\
\hline & $\mathrm{CMCH}^{1}{ }^{1}$ & $\mathrm{CMCH}^{2}{ }^{2}$ & $\mathrm{CMCH}^{2} 3^{3}$ & $\mathrm{CMCH}-4$ \\
\hline E. Coli (Figure A1) & $\mathrm{ND}^{*}$ & $P^{* *}$ & $\mathrm{ND} *$ & $P^{* *}$ \\
\hline \multirow[t]{3}{*}{ S. Aureus (Figure A2) } & $\mathrm{P} * *$ & $\mathrm{P} * *$ & $P^{* *}$ & $\mathrm{ND} *$ \\
\hline & \multicolumn{4}{|c|}{ Chattogram Maa-O-Shishu Hospital (CMOSH) } \\
\hline & CMOSH-1 $^{5}$ & $\mathrm{CMOSH}^{2}{ }^{6}$ & $\mathrm{CMOSH} 3^{7}$ & $\mathrm{CMOSH} 4^{8}$ \\
\hline E. Coli (Figure A3) & $\mathrm{ND} *$ & $\mathrm{P} * *$ & $P^{* *}$ & $P^{* *}$ \\
\hline S. Aureus (Figure A4) & $\mathrm{ND}^{*}$ & $\mathrm{P} * *$ & $\mathrm{P} * *$ & $\mathrm{P} * *$ \\
\hline
\end{tabular}

Additionally, for wastewater samples from $\mathrm{CMOSH}$, the greywater samples from the pipe outlet did not contain E. coli and S. aureus, but it had other enteric bacteria. Greywater collected five meters away from drainage showed the presence of E. coli and S. aureus. Blackwater from the pipe outlet and five meters away from the pipe outlet (from drainage) showed the presence of E. coli and S. aureus (Table 5 and Figures A3 and A4). Black- and greywater from $\mathrm{CMCH}$ that was released to common drainage did not contain E. coli but did containe S. aureus and other enteric bacteria. In comparison, greywater that was released from CMOSH did not have E. coli or S. aureus, but blackwater that was released from CMOSH had both E. coli and S. aureus.

\subsubsection{Antibiotic Sensitivity Test}

After confirming the presence of E. coli and S. aureus in the wastewater samples of both hospitals, the isolated bacteria were sub-cultured again to test their resistance to six antibiotics. Antibiotic resistance was interpreted using minimum inhibitory concentration (MIC) or zone diameter from CLSI, ASM, and BSAC standards. The result of antibiotic sensitivity is summarized in Table 6.

For $\mathrm{CMCH}$, greywater from drainage had E. coli that showed resistance against tetracycline (TET) (30 $\mu \mathrm{g} /$ discs), sulfamethoxazole-trimethoprim (SXT) $(25 \mu \mathrm{g} / \mathrm{discs})$, and amoxicillin (AMX) (30 $\mu \mathrm{g} / \mathrm{disc})$, while E. coli isolated from blackwater obtained from drainage showed resistance against ampicillin (AMP) (25 $\mu \mathrm{g} / \mathrm{disc}), \mathrm{SXT}(25 \mu \mathrm{g} / \mathrm{discs})$, AMX (30 $\mu \mathrm{g} / \mathrm{disc})$, and mecillinam (MEC) $(10 \mu \mathrm{g} / \mathrm{disc})$. Greywater of $\mathrm{CMCH}$ from drainage had $\mathrm{S}$. aureus that showed resistance only against ampicillin (10 $\mu \mathrm{g} / \mathrm{disc})$. MIC of S. aureus is not mentioned in CLSI and ASM, but in BSAC it was mentioned that "Most staphylococci are penicillinase producers, which are resistant to benzylpenicillin, phenoxymethylpenicillin, ampicillin, amoxicillin, and piperacillin" (BSAC). Antibiotic-resistant profiling of wastewater from CMCH had been conducted previously by other researchers. Findings revealed strains of $E$. coli that were resistant to TET, penicillin, ciprofloxacin, erythromycin [54,55].

For $\mathrm{CMOSH}$, greywater discharged from the hospital into the drainage had E. coli that exhibited resistance against AMP $(25 \mu \mathrm{g} / \mathrm{disc})$ and intermediate to AMX (30 $\mu \mathrm{g} / \mathrm{disc})$. E. coli from blackwater from the hospital pipe outlet of CMOSH showed resistance against AMX (30 $\mu \mathrm{g} / \mathrm{disc})$. Additionally, E. coli from the blackwater of CMOSH from drainage showed resistance against TET (30 $\mu \mathrm{g} / \mathrm{disc})$, AMP $(25 \mu \mathrm{g} / \mathrm{disc})$, SXT $(25 \mu \mathrm{g} / \mathrm{disc})$, and AMX (30 $\mu \mathrm{g} / \mathrm{disc})$. S. aureus from common drainage that greywater flowed through showed resistance against penicillin (P) $(10 \mu \mathrm{g} / \mathrm{disc})$ and MEC (10 $\mu \mathrm{g} / \mathrm{disc})$. $S$. aureus from the hospital outlet that blackwater was discharged through showed resistance against $P$

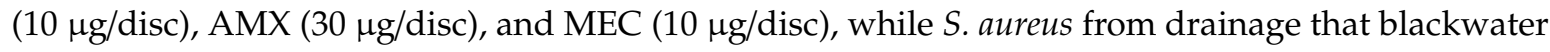
flowed through showed resistance against P (10 $\mu \mathrm{g} /$ disc) and AMX (30 $\mu \mathrm{g} / \mathrm{disc})$. 
Table 6. Antibiotic Sensitivity Test Results for Hospital Wastewater.

\begin{tabular}{|c|c|c|c|c|c|c|c|c|c|c|}
\hline \multirow{3}{*}{ Antibiotics } & \multicolumn{10}{|c|}{ E. coli } \\
\hline & \multicolumn{2}{|c|}{ CMCH-2 } & \multicolumn{2}{|c|}{ CMCH-4 } & \multicolumn{2}{|c|}{ CMOSH-2 } & \multicolumn{2}{|c|}{ CMOSH-3 } & \multicolumn{2}{|c|}{ CMOSH-4 } \\
\hline & Diameter (mm) & $\mathbf{S}, \mathbf{R}, \mathbf{I}^{* *}$ & Diameter (mm) & $\mathrm{S}, \mathrm{R}, \mathrm{I}$ ** & Diameter (mm) & $\mathrm{S}, \mathbf{R}, \mathrm{I} * *$ & Diameter $(\mathrm{mm})$ & $\mathrm{S}, \mathrm{R}, \mathrm{I}$ ** & Diameter (mm) & $\mathrm{S}, \mathbf{R}, \mathrm{I}^{* *}$ \\
\hline Tetracycline $(30 \mu \mathrm{g} /$ disc $)$ & NM & $\mathrm{R}$ & 18 & $\mathrm{~S}$ & 30 & $\mathrm{~S}$ & 15 & $\mathrm{~S}$ & NM & $\mathrm{R}$ \\
\hline Penicillin (10 units) & NM & $\mathrm{N}^{*}$ & NM & $\mathrm{N}^{*}$ & NM & $\mathrm{N}^{*}$ & NM & $\mathrm{N}^{*}$ & NM & $\mathrm{N}^{*}$ \\
\hline Ampicillin $(25 \mu \mathrm{g} / \text { disc })^{1}$ & NM & $\mathrm{R}$ & NM & $\mathrm{R}$ & NM & $\mathrm{R}$ & NM & $\mathrm{R}$ & NM & $\mathrm{R}$ \\
\hline $\begin{array}{l}\text { Sulfamethoxazole-Trimethoprim } \\
\qquad(25 \mu \mathrm{g} / \text { discs })^{2}\end{array}$ & NM & $\mathrm{R}$ & NM & $\mathrm{R}$ & 25 & $\mathrm{~S}$ & 25 & $\mathrm{~S}$ & NM & $\mathrm{R}$ \\
\hline Amoxicillin(30 $\mu \mathrm{g} / \mathrm{disc})$ & NM & $\mathrm{R}$ & NM & $\mathrm{R}$ & 15 & $\mathrm{I}$ & NM & $\mathrm{R}$ & NM & $\mathrm{R}$ \\
\hline Mecillinam (10 $\mu \mathrm{g} /$ disc) & 15 & $\mathrm{~S}$ & NM & $\mathrm{R}$ & 25 & $\mathrm{~S}$ & 18 & $\mathrm{~S}$ & 15 & $\mathrm{~S}$ \\
\hline \multicolumn{11}{|c|}{ S. aureus } \\
\hline Tetracycline $(30 \mu \mathrm{g} /$ disc $)$ & 15 & $\mathrm{I}$ & 35 & $\mathrm{~S}$ & 25 & $\mathrm{~S}$ & 30 & $\mathrm{~S}$ & 20 & $\mathrm{~S}$ \\
\hline Penicillin (10 units) & 25 & $\mathrm{R}$ & 12 & $\mathrm{R}$ & 20 & $\mathrm{R}$ & NM & $\mathrm{R}$ & 20 & $\mathrm{R}$ \\
\hline Ampicillin $(25 \mu \mathrm{g} /$ disc $)$ & 33 & $\mathrm{~S}$ & 15 & $\mathrm{R}$ & 30 & $\mathrm{~S}$ & NM & $\mathrm{R}$ & 20 & - \\
\hline $\begin{array}{l}\text { Sulfamethoxazole-Trimethoprim } \\
(25 \mu \mathrm{g} / \text { discs })^{2}\end{array}$ & 25 & $\mathrm{~S}$ & 30 & $\mathrm{~S}$ & 25 & $\mathrm{~S}$ & 40 & $\mathrm{~S}$ & 25 & $\mathrm{~S}$ \\
\hline Amoxicillin $(30 \mu \mathrm{g} / \text { disc })^{3}$ & 3 & $\mathrm{~N}^{*}$ & 15 & $\mathrm{~N}^{*}$ & 23 & $\mathrm{~S}$ & NM & $\mathrm{R}$ & NM & $\mathrm{R}$ \\
\hline Mecillinam (10 $\mu \mathrm{g} /$ disc $)$ & NM & $\mathrm{N}^{*}$ & NM & $\mathrm{N}^{*}$ & NM & $\mathrm{R}$ & NM & - & 15 & - \\
\hline
\end{tabular}

${ }^{1}$ For E. coli ampicillin $25 \mu \mathrm{g} /$ disc is not tested in the Clinical and Laboratory Standards Institute (CLSI), the British Society for Antimicrobial Chemotherapy (BSAC), or the American Society for Microbiology (ASM). However, CLSI included the standard ampicillin (10 $\mu \mathrm{g} / \mathrm{disc})$. This result is observed based on ampicillin (10 $\mu \mathrm{g} / \mathrm{disc}){ }^{2}{ }^{2}$ For sulfamethoxazole-trimethoprim ( $25 \mu \mathrm{g} / \mathrm{disc})$, there is no data on the mentioned standards. However, there is data for 1.25/23.75 $\mu \mathrm{g}$ and these values were predicted based on this concentration; ${ }^{3} \mathrm{Most}$ staphylococci are penicillinase producers, which are resistant to benzylpenicillin, phenoxymethylpenicillin, ampicillin, amoxicillin, and piperacillin. According to CLSI, the results from ampicillin can be used to predict the result for amoxicillin as well; ${ }^{*} \mathrm{~N}$ : in these three standards, the data for E. coli for penicillin (10 units) was not available; ** R: resistant, I: intermediate, S: susceptible. 
Similar to the findings of the antibiotic resistance test from this study, previous studies in Bangladesh found E. coli isolates from hospital wastewater that showed a high degree of resistance to AMP, TET, and SXT, as well as ceftazidime, cefotaxime, chloramphenicol, gentamycin, ciprofloxacin, streptomycin, kanamycin, imipenem, and azithromycin [36-39]. S. aureus showed $100 \%$ resistance to AMX in another study conducted in Chattogram, among other antibiotics like cefradin, colistin, cefalexin, oxytetracycline, and pefloxacin [56].

The high antibiotic resistance perceived in the wastewater samples is potentially due to antibiotic overuse in hospitals that induces growth in the population of resistant microbes. In fact, swab tests of different environmental surfaces conducted in tertiary hospitals of Chattogram revealed a high level of resistance of pathogens such as Streptococcus, Staphylococcus, Bacillus, Pseudomonas, and Serratia to commonly used antibiotics, resulting from uncontrolled antibiotic use in hospitals [57]. These resistant microbes are then released into the environment because of a lack of proper disposal of the antibiotic or treatment, which can later cause infections that may not be treatable using existing antibiotics, thereby increasing mortality and morbidity.

\subsubsection{Physicochemical Characterization of the Hospital Wastewater}

Collected wastewater samples' parameters were compared with Bangladesh Water Quality Standards. Measured parameters were: TDS, DO, conductivity, salinity, $\mathrm{BOD}_{5}$, and $\mathrm{pH}$, results of which are presented in Figure 2.

Effluent water from the hospitals had significantly lower DO and BOD than the prescribed guidelines by Bangladesh Water Quality Standards. The salinity was higher than the guidelines, albeit very little. According to WHO standards, which allow a pH level of 6 to 9, the $\mathrm{pH}$ of the effluent wastewater was within safe limits.

The study found better results for the physical parameter for hospital wastewater in Bangladesh. A study conducted in Iran found that many of the physical parameters evaluated in wastewater effluent of hospitals of Babol University of Medical Sciences were higher than effluent discharge standards of the Iran Environment Protection Agency (IEPA) [58].

\subsection{Limitations and Future Directions}

The study displayed the stark differences between the KAP of healthcare workers in public and private hospitals, which was important to show the limitations within each of the sectors. However, this study was subjected to time and resource constraints, which is why only two hospitals in the Chattogram division were selected as sample areas, which may not be diverse enough for generalizability. This study acknowledges that, even within the Chattogram division, there might be other hospitals following a different system for their hospital waste management, and the time limitations made a comprehensive measurement of the impacts of different kinds of hospital waste management a challenge. In addition, the practice score might have been overestimated in this study because the assessment was made through self-reporting. In addition to that, due to language barriers, a limited number of lab technicians and cleaners were included in the study. Finally, the reluctance of doctors and nurses to participate in the research was a major barrier.

An improvement that could have been brought in the study could be by the use of an ordinal regression model to extract more meaningful and useful findings from the KAP section of this study. Furthermore, the determination of the presence of antibiotics in hospital wastewater could have provided valuable insight, particularly when the amount available is compared with the resistance of E. coli and S. aureus. The scope of the biochemical analysis was restricted by a lack of availability of resources, such as the kinds of antibiotics against which resistance could be tested. More robust water sampling and quality analysis are required in future research. Composite sampling methods are recommended with further exploration of various other kinds of enteric pathogens. Most importantly, comprehensive physicochemical characterization of hospital wastewater in Chattogram is encouraged because this research area is heavily lacking compared to other industries such as tanneries and textile 
industries. As a scoping study, this study provides very basic indicators and parameters for water quality assessment, but several other physicochemical characteristics, such as COD, total organic carbon (TOC), and adsorbable organic halides (AOX), and an investigation into the presence of metals, could have made for better evaluation of the wastewater samples.

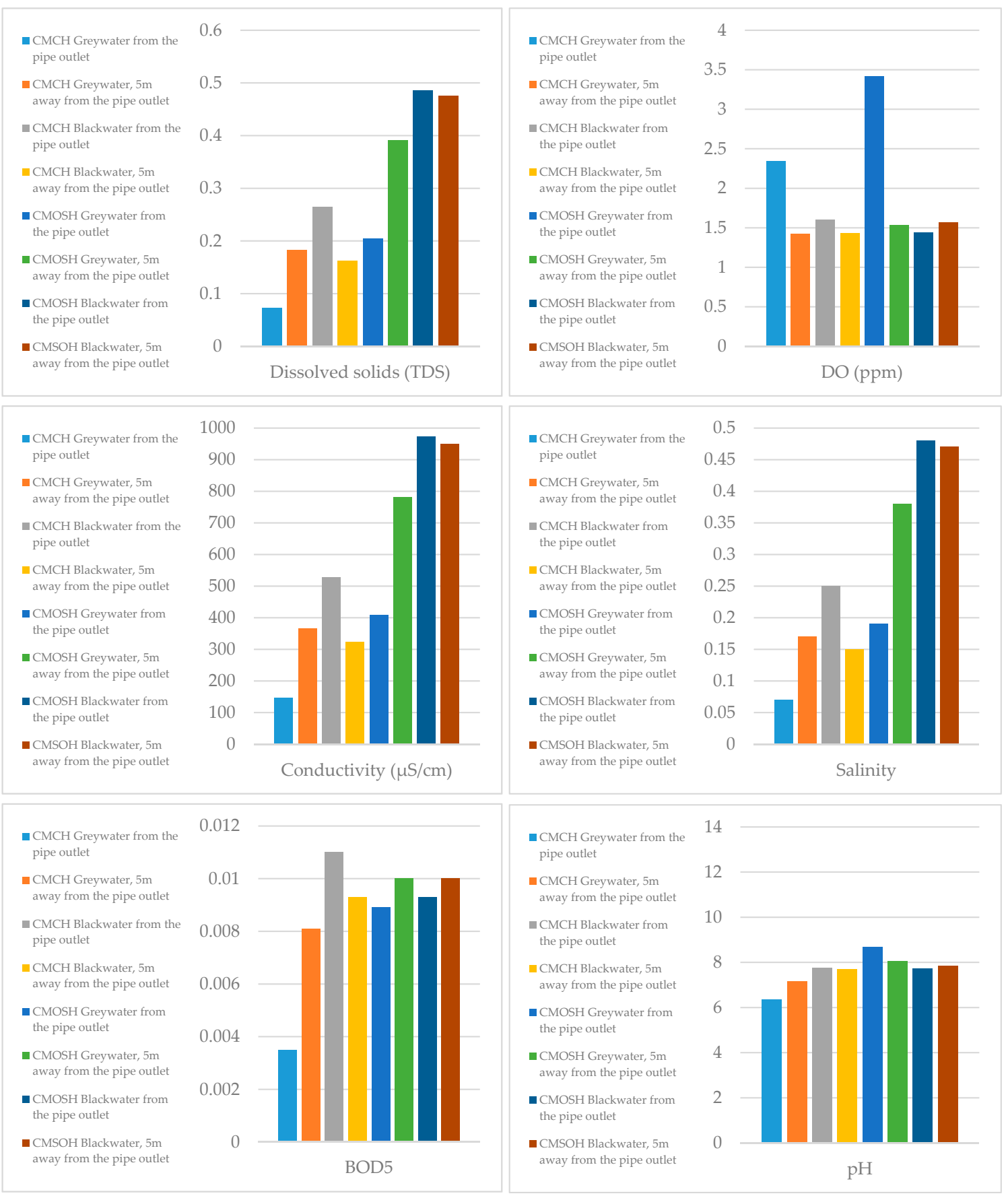

Figure 2. Results of Water Quality Parameters of Hospital Wastewater expressed in mg/L.

Despite these limitations, this study's findings could be used as baseline information for future researchers and policymakers. This paper has shown the institutional and structural flaws in the overall hospital waste management system in Chattogram. The study also was able to identify the poor condition of private hospitals in health-safety issues and occupational illness for the doctors and nurses compared to the public hospitals. Similar findings were also seen in studies previously done including both public and private and private hospitals [11]. Not only did it show the lack 
of trained and skilled personnel in hospitals for waste collection and disposal, but there is also a scarcity of safety equipment for those involved. The microbial risk and occupational hazards are a clear representation of the inadequacy in the system. Moreover, the practice of landfilling is not only harmful to the environment but has also proved to be unsustainable in the long run. Violations of guidelines provided by the Environmental Assessment and Action Plan (2004) [47] and the National Occupational Safety and Health Policy (2013) [19] were observed in several aspects. The study can, therefore, inform the healthcare and government authorities in Chattogram and, in fact, in Bangladesh and other developing or resource-scarce nations regarding the potential problems of the existing hospital waste management system.

\section{Conclusions}

This study attempted to present the potential environmental and public health risk contributed by the existing scenario of hospital waste management in Chattogram. Different aspects of hospital waste management, beginning with the KAP of handlers and others involved, to the management practices undertaken by the municipal government regarding solid waste and hospital wastewater, and the physicochemical and microbiological quality of the wastewater, were studied to explore opportunities for environmental and health hazards.

In both the private and public hospitals, the occupational safety of healthcare employees is not considered or maintained strictly. As a result, the health and safety of healthcare workers is compromised. The study found that these hospital wastes are not segregated properly, either in public or in private hospitals. Additionally, temporary storage within the hospitals is also not properly managed. In the end, all the wastes are disposed of together with municipal wastes in the CCC's open landfill. Unsafe disposal of hospital waste creates health hazards for waste pickers, homeless people living on streets and near dumpsters, and the general public.

While the physicochemical properties of the wastewater samples were nearly compliant with the Bangladesh Water Quality Standards for hospital wastewater, this study also examined the presence of E. coli and S. aureus in hospital wastewater where, most notably, blackwater samples from the private hospital showed the presence of both microbes, while the greywater sample from the public hospital contained S. aureus. Additionally, E. coli and S. aureus showed resistance against different antibiotics. These are crucial findings and needs quick action from the concerned authorities of these healthcare facilities. This study concludes that, in Bangladesh, the lack of proper management of hospital waste creates issues for public health, the environment, and waste pickers. Therefore, it is recommended to place focus on appropriate hands-on advanced training for the hospital waste handlers and other individuals involved in hospital waste management and to increase their awareness and knowledge. The use of appropriate protective equipment such as gloves, goggles, and masks should be encouraged while handling any hazardous waste to minimize the occupational health hazard. Most importantly, regular monitoring and audit should be practiced, ensuring the proper handling of these hospital wastes.

Author Contributions: Conceptualization, B.B. and S.M.N.U.; methodology, B.B. and S.M.N.U.; validation, B.B. and S.M.N.U.; formal analysis, B.B.; investigation, B.B.; resources, S.M.N.U. and A.M.M.; data curation, B.B.; writing-original draft preparation, B.B.; writing-review and editing, S.N.O., S.M.N.U., N.R., S.M.N., A.M.M., and M.H.; visualization, B.B., S.N.O., S.M.N.U., S.M.N., and N.R.; supervision, S.M.N.U.; project administration, B.B. and S.M.N.U.; funding acquisition, B.B. All authors have read and agreed to the published version of the manuscript.

Funding: This research received no external funding.

Acknowledgments: Lab support from Fatema-Tuz-Zohora, Nabila Ishaque, and Rahul Das is highly acknowledged. Special thanks to Fahmida Rashid for her administrative support and permission process in Chattogram Medical College Hospital and Chattogram Maa-O-Shishu Hospital. Field and translation support from Zuhairia Ibnat, Zannatul Ferdous Munmun, Muntasha Nahrin, and Saifur Rahaman Faisal are also acknowledged.

Conflicts of Interest: The authors declare no conflict of interest. 


\section{Appendix A}

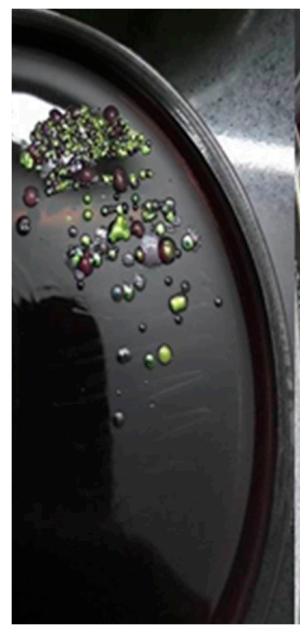

$\mathrm{CMCH}-1$

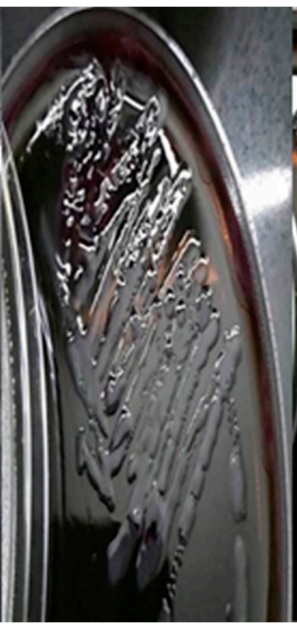

$\mathrm{CMCH}-2$

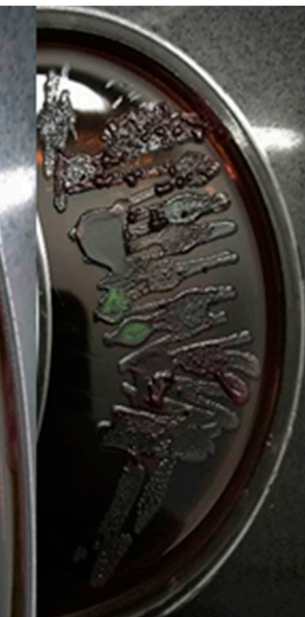

$\mathrm{CMCH}-3$

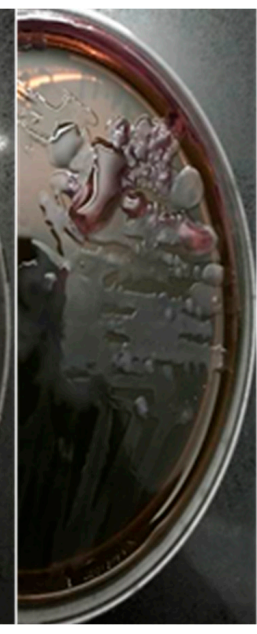

$\mathrm{CMCH}-4$

Figure A1. E. coli culture of wastewater from Chattogram Medical College Hospital on EMB agar.

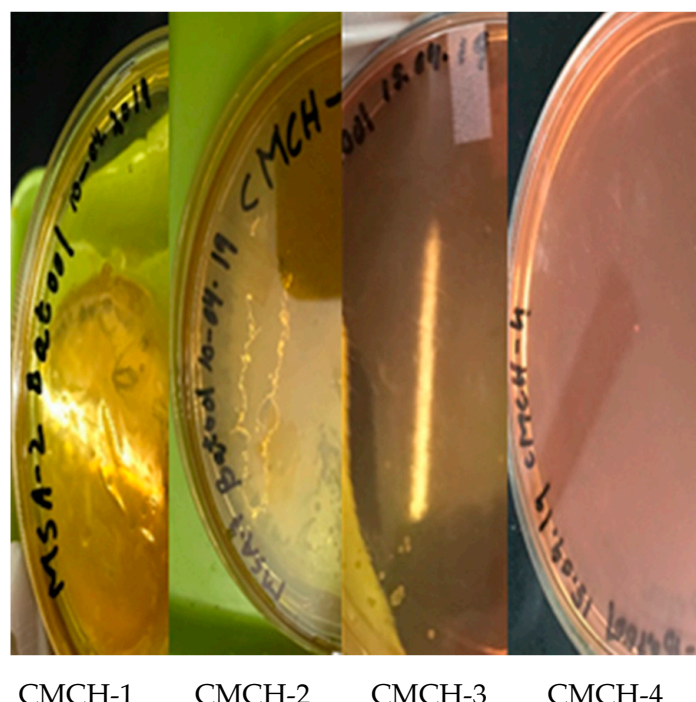

Figure A2. S. aureus culture of wastewater from Chattogram Medical College Hospital on MSA agar.

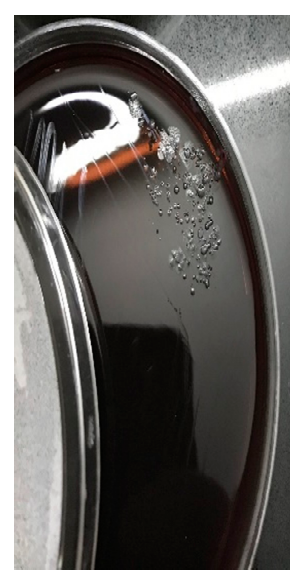

CMOSH-1

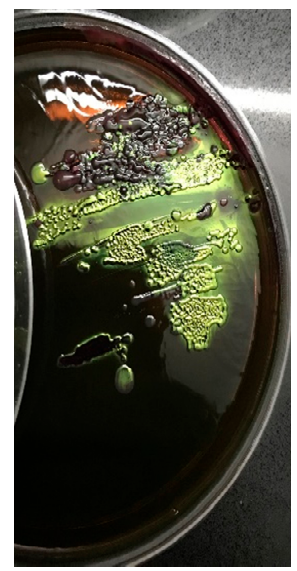

$\mathrm{CMOSH}-2$

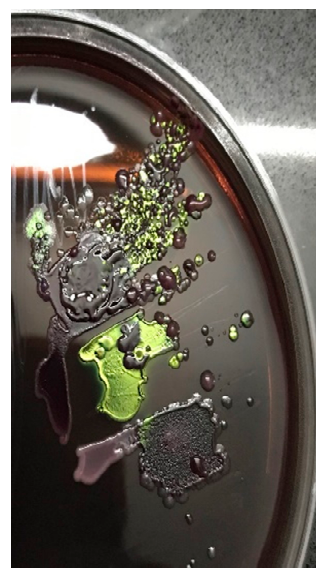

$\mathrm{CMOSH}-3$

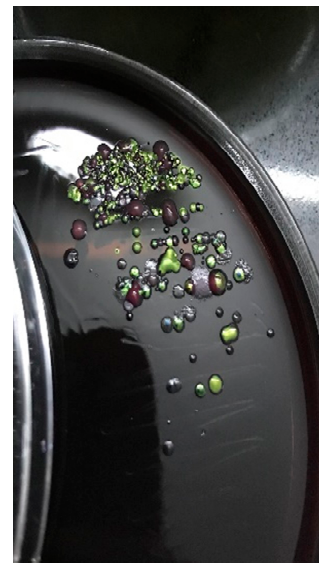

CMOSH-4

Figure A3. E. coli culture of wastewater from Chattogram Maa-O-Shishu Hospital on EMB agar. 


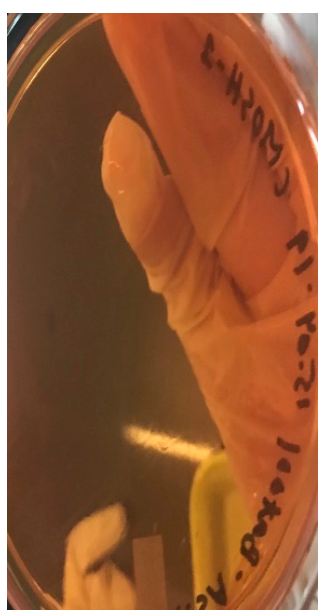

CMOSH-1

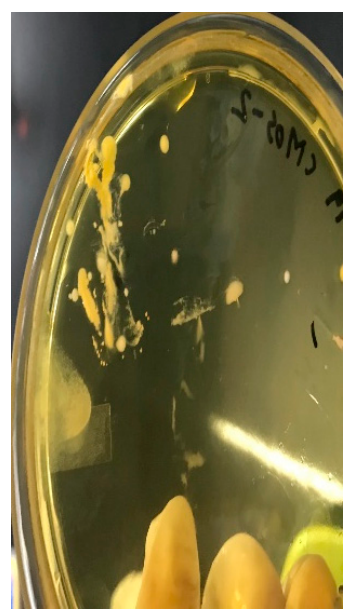

CMOSH-2

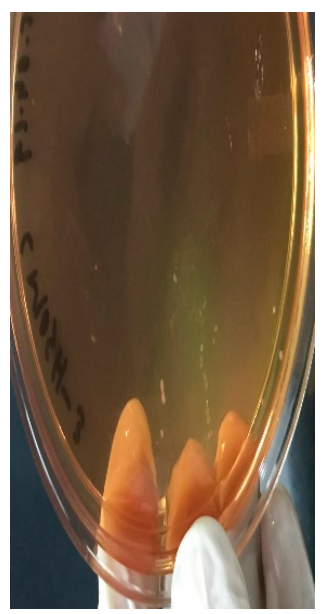

$\mathrm{CMOSH}-3$

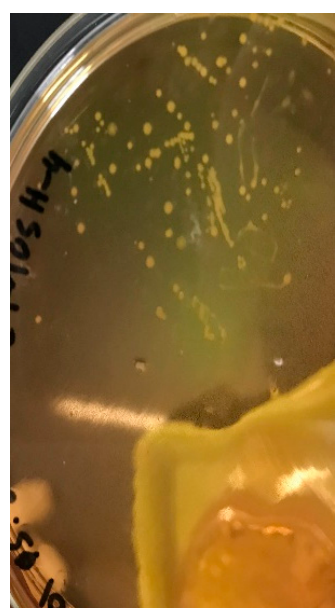

$\mathrm{CMOSH}-4$

Figure A4. S. aureus culture of wastewater from Chattogram Maa-O-Shishu Hospital on MSA agar.

\section{References}

1. WHO. Safe Management of Wastes from Health-Care Activities, 2nd ed.; Available online: https://www.who.int/ iris/bitstream/10665/85349/1/9789241548564_eng.pdf?ua=1 (accessed on 3 September 2020).

2. Windfeld, E.S.; Brooks, M.S.L. Medical waste management-A review. J. Environ. Manag. 2015, 163, 98-108. [CrossRef] [PubMed]

3. Halling-Sørensen, B.N.N.S.; Nielsen, S.N.; Lanzky, P.F.; Ingerslev, F.; Lützhøft, H.H.; Jørgensen, S.E. Occurrence, fate and effects of pharmaceutical substances in the environment-A review. Chemosphere 1998, 36, 357-393. [CrossRef]

4. Ubuoh, E.A.; Ezenwa, L.E.; Ndukwu, M.C.; Emeka-Chris,C.C. Assessment of cation chemistry of groundwater near hospital wastes dumpsites in Umuahia Nigeria using multivariate and analytical index approach. Environ. Technol. Innov. 2019, 15, 100371. [CrossRef]

5. WHO. Global Strategy on Human Resources for Health: Workforce 2030. Available online: https://www. who.int/hrh/resources/pub_globstrathrh-2030/en/ (accessed on 3 September 2020).

6. UNHRC. Medical Waste and Human Rights, UN Human Rights Council, Philippines. Available online: https:// noharm-europe.org/sites/default/files/documents-iles/1684/MedWaste_Human_Rights_Report.pdf (accessed on 3 September 2020).

7. Ali, M.; Wang, W.; Chaudhry, N.; Geng, Y. Hospital waste management in developing countries: A mini review. Waste Manag. Res. 2017, 35, 581-592. [CrossRef] [PubMed]

8. Nuralam, H.M.; Xiao-lan, Z.; Dubey, B.K.; Wen-Chuan, D. Healthcare Waste Management Practices in Bangladesh: A Case Study in Dhaka City, Bangladesh. Int. J. Environ. Ecol. Eng. 2017, 11, 534-539.

9. Rumi, M.Y.; Karim, R. Determining the Hazardous Medical Waste Generation Rates of Private Health Care Facilities-Case Study from Dhaka City of Bangladesh. Am. J. Environ. Sci. 2018, 14, 203-211. [CrossRef]

10. Uddin, M.N.; Islam, M.R.; Yesmin, K. Knowledge on hospital waste management among senior staff nurses working in a selected medical college hospital of Bangladesh. J. Waste Manag. 2014. [CrossRef]

11. Akter, K.S.; Reza, S.M.S. Awareness on Medical Waste Management and Occupational Health Safety among the employees Related to Medical Services at Upazila level in Bangladesh. J. Environ. Treat. Tech. 2019, 7 , $282-288$.

12. Sumon, S. Bangladesh loses doctors to COVID-19. Available online: https://www.arabnews.com/node/ 1689996/world (accessed on 29 August 2020).

13. Prüss-Üstün, A.; Rapiti, E.; Hutin, Y. Estimation of the global burden of disease attributable to contaminated sharps injuries among health-care workers. Am. J. Ind. Med. 2005, 48, 482-490. [CrossRef] [PubMed]

14. Moses, C.S. Risks to Health Care Workers in Developing Countries. N. Engl. J. Med. 2007, 345, 538-541. [CrossRef]

15. Uddin, M.S.; Islam, M.N.; Khan, M.E.U.; Yeasmin, S.; Ahmed, F.; Amiruzzaman, M. Frequency of Hepatitis B and C Viral Infection among the Medical Waste Handlers. Bangladesh J. Infect. Dis. 2017, 4, 3-9. [CrossRef] 
16. Akter, N.; Tränkler, J. An analysis of possible scenarios of medical waste management in Bangladesh. Manag. Environ. Qual. Int. J. 2003, 14, 242-255. [CrossRef]

17. WHO. Occupational Health A Manual for Primary Health Care Workers. Available online: https://www. who.int/occupational_health/regions/en/oehemhealthcareworkers.pdf?ua=1 (accessed on 3 September 2020).

18. Anozie, O.B.; Lawani, L.O.; Eze, J.N.; Mamah, E.J.; Onoh, R.C.; Ogah, E.O.; Umezurike, D.A.; Anozie, R.O. Knowledge, attitude and practice of healthcare managers to medical waste management and occupational safety practices: Findings from Southeast Nigeria. J. Clin. Diagn. Res. 2017, 11, IC01. [CrossRef] [PubMed]

19. Bangladesh Institute of Labour Studies-BILS. Occupational Safety and Health In Bangladesh: National Profile. Available online: https://www.google.com/url?sa=t\&rct=j\&q=\&esrc=s\&source=web\&cd=\&ved= 2ahUKEwjqytOHn5HsAhVMU30KHZI9AfMQFjAAegQIAxAB\&url=http\%3A\%2F\%2Fbilsbd.org\%2Fwpcontent\%2Fuploads\%2F2016\%2F03\%2FBILS-ILO-Study_OSH-Profile_Final-Report_29-June-2015.pdf\& usg=AOvVaw2GJrtpkxplkOO94d-qvEqZ (accessed on 30 September 2020).

20. Ahmed, F.; Ansari, M.S.; Rahman, M.M.S.; Saha, S.K.; Roy, K. Assessment of occupational health and safety management services: A study from different hospitals and clinics in Khulna city corporation of Bangladesh. Bangladesh J. Environ. Sci. 2011, 21, 87-94.

21. Akter, N. Medical Waste Management: A Review; BRAC University, Dhaka, Bangladesh and Asian Institute of Technology: Pathum Thani, Thailand, 2000.

22. Nasrin, F. Waste management in Bangladesh: Current situation and suggestions for action. Int. Res. J. Soc. Sci. 2016, 5, 36-42.

23. Syed, E.H.; Mutahara, M.; Rahman, M. Medical Waste Management (MWM) in Dhaka, Bangladesh. Home Health Care Manag. Pract. 2012, 24, 140-145. [CrossRef]

24. Hassan, M.M.; Ahmed, S.A.; Rahman, K.A.; Biswas, T.K. Pattern of medical waste management: Existing scenario in Dhaka City, Bangladesh. BMC Public Health 2008, 8, 36. [CrossRef]

25. Alam, O.; Hossain, M. A comparative study on the differences between public and private healthcare entities in healthcare waste management in Chittagong, Bangladesh. In Proceedings of the WasteSafe 2013-3rd International Conference on Solid Waste Management in the Developing Countries, Khulna, Bangladesh, 10-12 February 2013.

26. Alam, M.Z.; Islam, M.S.; Islam, M.R. Medical Waste Management: A Case Study on Rajshahi City Corporation in Bangladesh. J. Environ. Sci. Nat. Resour. 2013, 6, 173-178. [CrossRef]

27. Maksud, A.K.M. Contribution of the waste pickers of Dhaka city in recycling and waste management. Int. J. Waste Resour. 2017, 7. [CrossRef]

28. Rizwan, F. Disease and Health Condition of Scavengers in Bangladesh. Master's Thesis, East West University, Dhaka, Bangladesh, 2016.

29. Saadat, S.; Rawtani, D.; Hussain, C.M. Environmental perspective of COVID-19. Sci. Total Environ. 2020, 728, 138870. [CrossRef]

30. Hocquet, D.; Muller, A.; Bertrand, X. What happens in hospitals does not stay in hospitals: Antibiotic-resistant bacteria in hospital wastewater systems. J. Hosp. Infect. 2016, 93, 395-402. [CrossRef] [PubMed]

31. Smith, R.D.; Yago, M.; Millar, M.; Coast, J. Assessing the macroeconomic impact of a healthcare problem: The application of computable general equilibrium analysis to antimicrobial resistance. J. Health Econ. 2005, 24, 1055-1075. [CrossRef] [PubMed]

32. UNICEF; WHO. Progress on Household Drinking Water, Sanitation and Hygiene: 2000-2017. Special Focus on Inequalities. Available online: https:/washdata.org/sites/default/files/documents/reports/2019-07/jmp2019-wash-households.pdf (accessed on 30 September 2020).

33. Ahmed, I.; Rabbi, M.B.; Sultana, S. Antibiotic resistance in Bangladesh: A systematic review. Int. J. Infect. Dis. 2019, 80, 54-61. [CrossRef] [PubMed]

34. Rahman, M.; Huys, G.; Rahman, M.; Albert, M.J.; Kühn, I.; Möllby, R. Persistence, transmission, and virulence characteristics of Aeromonas strains in a duckweed aquaculture-based hospital sewage water recycling plant in Bangladesh. Appl. Environ. Microbiol. 2007, 73, 1444-1451. [CrossRef] [PubMed]

35. UN-Water. Wastewater: An Untapped Resource. Available online: https://unesdoc.unesco.org/ark:/48223/ pf0000247153 (accessed on 30 September 2020).

36. Akther, S.; Debnath, T.; Chowdhury, M.M.H. Multidrug Resistant E. coli in hospital waste water: A potential concern for public health. Adv. Biotechnol. Microbiol. 2018, 8. [CrossRef] 
37. Adnan, N.; Sultana, M.; Islam, O.K.; Nandi, S.P.; Hossain, M.A. Characterization of ciprofloxacin resistant extended spectrum $\beta$-lactamase (ESBL) producing Escherichia spp. from clinical waste water in Bangladesh. Adv. Biosci. Biotechnol. 2013, 4. [CrossRef]

38. Rabbani, M.A.G.; Howlader, M.Z.H.; Kabir, Y. Detection of multidrug resistant (MDR) bacteria in untreated waste water disposals of hospitals in Dhaka City, Bangladesh. J. Glob. Antimicrob. Resist. 2017, 10, 120-125. [CrossRef]

39. Islam, M.A.; Islam, M.; Hasan, R.; Hossain, M.I.; Nabi, A.; Rahman, M.; Goessens, W.H.F.; Endtz, H.P.; Boehm, A.B.; Faruque, S.M. Environmental spread of New Delhi metallo- $\beta$ lactamase-1-producing multidrug-resistant bacteria in Dhaka, Bangladesh. Appl. Environ. Microbiol. 2017, 83, e00793-17. [CrossRef]

40. Hossain, M.B.; Islam, M.N.; Alam, M.S.; Hossen, M.Z. Industrialisation scenario at Sreepur of Gazipur, Bangladesh and physico-chemical properties of wastewater discharged from industries. Asian J. Environ. Ecol. 2019, 1-14. [CrossRef]

41. Islam, S.; Islam, F.; Bakar, M.A.; Das, S.; Bhuiyan, H.R. Heavy metals concentration at different tannery wastewater canal of Chittagong city in Bangladesh. Int. J. Agric. Environ. Biotechnol. 2013, 6, 355-362. [CrossRef]

42. Ali, M.K.; Sarraz, A.; Roy, P.K.; Nahar, A.M.; Jubaer, A.; Das, S.; Mallick, R. Environmental Assessment of Industrial Wastewater in Chittagong City-Bangladesh. Int. J. Sci. Technol. 2017, 6, 733-741.

43. Yaşar, A.; Can Doğan, E.; Arslan, A. Macro and Micro Pollutants and Treatment Options in Hospital Wastewaters. Erciyes Univ. J. Inst. Sci. Technol. 2013, 2, 144-158.

44. NCBI. Tertiary Care Centers. Available online: https://www.ncbi.nlm.nih.gov/mesh?Db=mesh\&term= Tertiary+Care+Centers (accessed on 1 October 2020).

45. Ministry of Health and Family Welfare (MOHFW). Health Bulletin 2016. Available online: http://app. dghs.gov.bd/localhealthBulletin2016/publish/publish.php?org=10000750\&year=2016\&lvl=3 (accessed on 2 October 2020).

46. Martínez-Mesa, J.; González-Chica, D.A.; Duquia, R.P.; Bonamigo, R.R.; Bastos, J.L. Sampling: How to select participants in my research study? An. Bras. Dermatol. 2016, 91, 326-330. [CrossRef]

47. Ministry of Health and Family Welfare (MOHFW). Environmental Assessment and Action Plan for the Health, Population and Nutrition Sector Development Program (HPNSDP) 2011-2016. Available online: http://www.mohfw.gov.bd/index.php?option=com_docman\&task=doc_download\&gid= 359\&Itemid=\&lang=en (accessed on 2 October 2020).

48. Mugabi, B.; Hattingh, S.; Chima, S.C. Assessing knowledge, attitudes, and practices of healthcare workers regarding medical waste management at a tertiary hospital in Botswana: A cross-sectional quantitative study. Niger. J. Clin. Pract. 2018, 21, 1627-1638. [CrossRef]

49. Olaifa, A.; Govender, R.D.; Ross, A.J. Knowledge, attitudes and practices of healthcare workers about healthcare waste management at a district hospital in KwaZulu-Natal. S. Afr. Fam. Pract. 2018, 60, 137-145. [CrossRef]

50. Sarker, M.A.B.; Harun-Or-Rashid, M.; Hirosawa, T.; Hai, M.S.B.A.; Siddique, M.R.F.; Sakamoto, J.; Hamajima, N. Evaluation of knowledge, practices, and possible barriers among healthcare providers regarding medical waste management in Dhaka, Bangladesh. Medical Science Monitor. Int. Med. J. Exp. Clin. Res. 2014, 20, 2590.

51. Bhattacharjee, S.; Saha, B. Study Of Knowledge, Attitude And Practices Regarding Biomedical Waste Management Among Healthcare Personnel In Gazipur, Bangladesh. Life Sci. Int. J. 2015, 1, 1-6.

52. Madhukumar, S.; Ramesh, G. Study about awareness and practices about health care waste management among hospital staff in a medical college hospital, Bangalore. Iran. J. Basic Med. Sci. 2012, 3, 7-11.

53. Hussain, A. Chittagong Wasa to Launch Massive Sewerage Treatment Project. Available online: https:/www.dhakatribune.com/bangladesh/nation/2018/03/22/chittagong-wasa-launch-massivesewerage-treatment-project (accessed on 12 October 2020).

54. Islam, M.J.; Uddin, M.S.; Hakim, M.A.; Das, K.K.; Hasan, M.N. Role of untreated liquid hospital waste to the development of antibiotic resistant bacteria. J. Innov. Dev. Strategy 2008, 2, 17-21.

55. Akter, F.; Amin, M.R.; Osman, K.T.; Anwar, M.N.; Karim, M.M.; Hossain, M.A. Ciprofloxacin-resistant Escherichia coli in hospital wastewater of Bangladesh and prediction of its mechanism of resistance. World J. Microbiol. Biotechnol. 2012, 28, 827-834. [CrossRef] [PubMed] 
56. Ahaduzzaman, M.; Hassan, M.M.; Alam, M.; Islam, S.K.M.A.; Uddin, I. Antimicrobial resistance pattern against Staphylococcus aureus in environmental effluents. Res. J. Vet. Pract. 2014, 2, 13-16. [CrossRef]

57. Ira, N.I.; Marjana, N.; Mollah, A.K.M. Antibiotic Resistance Bacteria in Tertiary Hospitals in Chittagong, Bangladesh. Int. J. Sci. Eng. Sci. 2019, 3, 18-21.

58. Amouei, A.; Asgharnia, H.; Fallah, H.; Faraji, H.; Barari, R.; Naghipour, D. Characteristics of Effluent Wastewater in Hospitals of Babol University of Medical Sciences, Babol, Iran. Health Scope 2015, 4, e23222. [CrossRef]

Publisher's Note: MDPI stays neutral with regard to jurisdictional claims in published maps and institutional affiliations.

(C) 2020 by the authors. Licensee MDPI, Basel, Switzerland. This article is an open access article distributed under the terms and conditions of the Creative Commons Attribution (CC BY) license (http://creativecommons.org/licenses/by/4.0/). 